\title{
PUBERTY IN SUFFOLK AND CROSS-BRED RAMS
}

\author{
J. D. SKINNER AND L. E. A. ROWSON \\ A.R.C. Unit of Reproductive Physiology and Biochemistry,* \\ University of Cambridge
}

\section{(Received 18th December 1967)}

\begin{abstract}
Summary. Changes during puberty were studied in the live ram lamb by collecting electro-ejaculates and measuring fructose and citric acid concentration and sperm density and morphology. Fructose and citric acid secretion preceded spermatogenesis. Sperm motility improved with decreasing numbers of abnormal spermatozoa. Observations are included on the separation of the penis from the prepuce. In addition, the influence of season of birth on lamb ejaculates was studied. Reproductive development in lambs born in late summer was delayed, androgen secretion being more markedly affected than spermatogenesis. The results of these studies support the view that the onset of male puberty coincides with the time when the testes become androgenically active, the accessory glands begin to secrete fructose and citric acid, and the animal exhibits characteristic male behaviour.
\end{abstract}

\section{INTRODUCTION}

There have been, so far, only few studies on sexual development in the living pubescent ram, and, apart from the recent study of Skinner, Booth, Rowson \& Karg (1968), information on the endocrine function of the lamb testis is practically non-existent. The reports so far published on ejaculates from pubescent rams refer mainly to the German Merino and indigenous African breeds (Dun, 1955; Symington, 1961; Louw \& Joubert, 1964). Moreover, they concern only rams older than 98 days and are confined to observations on the appearance of spermatozoa. The breakdown of penile adhesions to the prepuce has been morphologically described in the Merino (Johnstone, 1948; Dun, 1955; Watson, Sapsford \& McCance, 1956; Belonje, 1965), Columbia, Targhee and Rambouillet (Wiggins \& Terrill, 1953). The main object of the present study was to investigate the time relationship between the development of the androgenic and gametogenic function of the pubescent ram testis. In addition, a small experiment was undertaken with cross-bred lambs to investigate the effects of season on the process of sexual development.

\section{MATERIALS AND METHODS}

Eighteen Suffolk lambs born in February/March were used to study puberty in this breed. Twelve cross-bred (Suffolk $\times$ Welsh Mountain) lambs were used

* Postal address: Animal Research Station, 307 Huntingdon Road, Cambridge. 
to study the effect of birth date on sexual function. Six of these lambs were born in February/March, and will be referred to as spring lambs, and six were born in July/August and will be referred to as late summer lambs. Data from six mature Suffolk rams have been included for comparison. The lambs were weaned at $3 \frac{1}{2}$ months when supplementary creep feeding was provided at a rate of $\frac{1}{2} \mathrm{lb}$ pelleted concentrates per day (Diet 302, BOCM Ltd).

Semen was collected by electrical stimulation (Rowson \& Murdoch, 1954) at weekly intervals, using a polypropylene probe $25 \mathrm{~cm}$ long and $2 \mathrm{~cm}$ diameter, with four embedded brass electrodes, $7 \mathrm{~cm}$ long and $0.5 \mathrm{~cm}$ wide, alternately connected; the probe was inserted to a depth of about $12 \mathrm{~cm}$ inside the anus. Attempts to collect semen by electro-ejaculation were made from 30 days of age onwards. In the spring lambs, Suffolk and cross-bred, these attempts were successful at 42 days of age but in the late summer lambs not until 63 days of age. The total ejaculate was obtained, the appearance noted and volume recorded at weekly intervals.

Immediately after collection, a sample of semen was examined under the microscope for the presence of spermatozoa and to observe their motility. If no spermatozoa were present the ejaculate was frozen in solid $\mathrm{CO}_{2}$. When spermatozoa first appeared samples were taken after complete ejaculation for nigrosin-eosin staining (Campbell, Dott \& Glover, 1956) and haemocytometer counts. When sperm density increased, the bulk of the ejaculate was collected into test tubes in dry ice but a small volume was collected into a separate tube for staining and counting. The percentage of live spermatozoa was determined from the nigrosin-eosin stained slides as well as the morphological abnormalities as classified by Blom (1950).

Fructose and citric acid determinations were carried out according to the methods of Roe (1934) and Speck, Moulder, \& Evans (1946), respectively, as modified by Mann (1946, 1964) and Mann, Davies \& Humphrey (1949). Estimations were made on samples of seminal plasma after centrifugation to remove the spermatozoa so that the estimates were made on the same volume. of seminal plasma in each case.

Observations were made on the separation of the processus urethrae from the penis, and of the penis from the prepuce.

At autopsy, which was carried out at 168 days of age, the testes and accessory glands were weighed, slices fixed in Bouin's fluid or Zenker-formol and the seminal vesicles removed and stored in solid carbon dioxide for the later assays of fructose and citric acid. The numbers of spermatozoa in the cauda epididymides of the Suffolks were counted following autopsy, as described by Dott \& Skinner (1967), and compared with the numbers found in six mature rams. The whole reproductive tract was also compared with that of mature Suffolk rams and the amount of fructose and citric acid in the seminal vesicles estimated according to the method of Lindner \& Mann (1960). The mean seminiferous tubule diameter was calculated from measurements of twenty-five tubules as described by Hay, Lindner \& Mann (1961).

Correlation coefficients were calculated between ejaculate volume, fructose concentration and content, and citric acid concentration and content, in the Suffolk ejaculates from 14 to 24 weeks of age. 


\section{RESULTS}

Observations on pubescent Suffolk rams, concerning semen and reproductive tract

Ejaculates were collected from 42 days of age. The first fructose estimations were carried out at this time but sufficient semen for citric acid assays only became available at 84 days of age. The main results of the chemical analyses of semen are illustrated in Text-fig. 1. The ratio of citric acid concentration to fructose concentration in the ejaculates was 36:64 at 84 days, and increased to $46: 54$ at 168 days. At first the ejaculate was translucent, but from about 84 days of age a large number of 'globules' appeared giving the ejaculate a 'cloudy' appearance resembling one in which spermatozoa are present. A

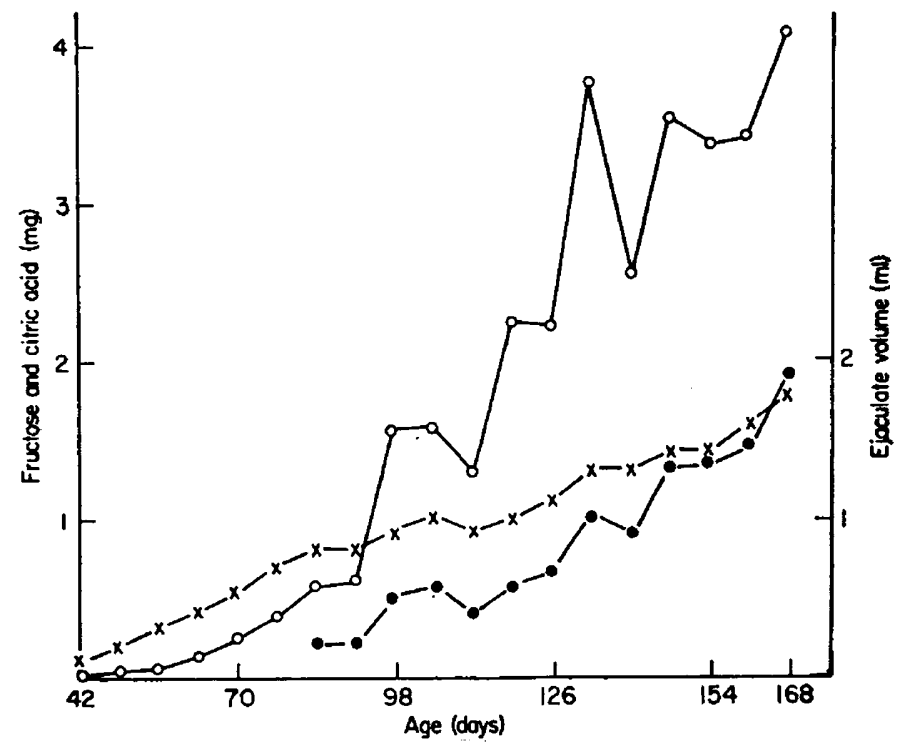

TEXT-Fig. 1. Mean volume $(X)$, and the content of fructose $(0)$ and citric acid $(\bullet)$ in electro-ejaculate collected from eighteen Suffolk lambs, varying in age from 42 to 168 days.

viscid mucus-like substance was also noticed in the semen at this time but soon disappeared as the lambs grew older. The number of 'globules' in the ejaculate, however, increased and large numbers were soon present and tended to aggregate. They stained with Sudan black, which indicates the presence of lipid. After spermatozoa appeared, the proportion of 'globules' decreased with increasing numbers of spermatozoa until finally no more 'globules' were apparent in the denser samples. The 'globules' are illustrated in Plate 1 (Figs. 1 to 3 ).

Correlation coefficients were significantly positive $(P<0.001)$ for ejaculate volume and fructose content: 0.42 (between ages, within animals) and 0.20 (within animals and ages); ejaculate volume and citric acid content: 0.60 (between ages, within animals) and 0.33 (within animals and ages); fructose concentration and citric acid concentration: 0.47 and 0.45 ; fructose content and citric acid content: 0.63 and 0.53 . Fructose and citric acid concentrations, however, were not significantly correlated with ejaculate volume. 
The mean volume of the ejaculate when spermatozoa first appeared was $1.1 \mathrm{ml}$. The time when spermatozoa first appeared in the ejaculate and the body weight at that time are compared with other breeds in Table 1 . The proportion of morphologically abnormal spermatozoa at 126 days and 6 weeks later and the percentage motile spermatozoa at both ages are compared in Table 2. Both the total number and concentration of spermatozoa increased

TABLE 1

AGE AND LIVE WEIGHT OF LAMBS AT THE TIME OF APPEARANCE OF SPERMATOZOA IN THE EJAGULATE, IN DIFFERENT BREEDS OF SHEEP

\begin{tabular}{|c|c|c|c|c|c|c|}
\hline \multirow{2}{*}{ Breed } & \multirow{2}{*}{$\begin{array}{c}\text { No. of } \\
\text { rams }\end{array}$} & \multicolumn{2}{|c|}{ Age (days) } & \multicolumn{2}{|c|}{ Weight $(\mathrm{kg})$} & \multirow{2}{*}{ Reference } \\
\hline & & Mean \pm S.E. & Range & Mean \pm S.E. & Range & \\
\hline Merino & 10 & 200 & $185-213$ & $28 \cdot 6$ & $24 \cdot 5-33 \cdot 2$ & Dun (1955) \\
\hline German Merino & 3 & 250 & - & $35 \cdot 9$ & - & Symington (1961) \\
\hline $\begin{array}{l}\text { Persian } \\
\text { Rhodesian }\end{array}$ & 4 & 224 & - & $21 \cdot 8$ & - & Symington (1961) \\
\hline indigenous & 3 & 169 & - & $20 \cdot 9$ & - & Symington (1961) \\
\hline Dorper & 20 & $128 \pm 2 \cdot 3$ & $112-145$ & $27 \cdot 3 \pm 0 \cdot 78$ & - & Louw \& Joubert (1964) \\
\hline \multirow{3}{*}{$\begin{array}{c}\text { Welsh Mountain } \\
\times \text { Suffolk } \\
\text { Born in spring } \\
\text { Born in late } \\
\text { summer }\end{array}$} & & & & & & \\
\hline & 6 & $117 \pm 6 \cdot 0$ & $103-131$ & $29 \cdot 9 \pm 0.58$ & $27 \cdot 3-32 \cdot 7$ & Present study \\
\hline & 6 & $138 \pm 6 \cdot 9$ & $122-168$ & $20 \cdot 3 \pm 0.95$ & $17 \cdot 3-23 \cdot 6$ & Present study \\
\hline Suffolk & 18 & $126 \pm 2 \cdot 2$ & $115-146$ & $36 \cdot 8 \pm 1 \cdot 40$ & $29 \cdot 5-50 \cdot 0$ & Present study \\
\hline
\end{tabular}

TABLE 2

MORPHOLOGICAL GHARACTERISTICS OF SPERMATOZOA IN ELEGTRO-EJAGULATES OF PUBESGENT RAMS AT DIFFERENT AGES

\begin{tabular}{l|c|c}
\hline & 126 days & 168 days \\
\cline { 1 - 2 } No. of rams & 15 & 15 \\
Spermatozo/ejaculate $\left(\times 10^{6}\right)$ & 45 & 803 \\
Live spermatozoa $(\%)$ & 65 & 81 \\
Motile spermatozoa $(\%)$ & 22 & 62 \\
Abnormal spermatozoa $(\%)$ & & \\
Deformed heads & 18 & 7 \\
$\quad$ Abaxial attachment & 4 & 2 \\
Coiled and looped tails & 8 & 5 \\
Tail-less & 15 & 11 \\
Proximal droplet & 25 & 6 \\
& & \\
\hline
\end{tabular}

steadily from the time of first appearance. In some rams the first spermatozoa were immotile but motility improved with increasing sperm concentration and a concomitant decrease in the number of abnormal spermatozoa.

A free processus urethrae loosely hung from the penis was observed from the age of about 63 to 70 days, and a live weight of about $27 \mathrm{~kg}$. Separation of the penis from the prepuce was already advanced by this stage, and was completed soon after.

The findings made at autopsy are listed in Table 3. They concern the 
PLATL 1
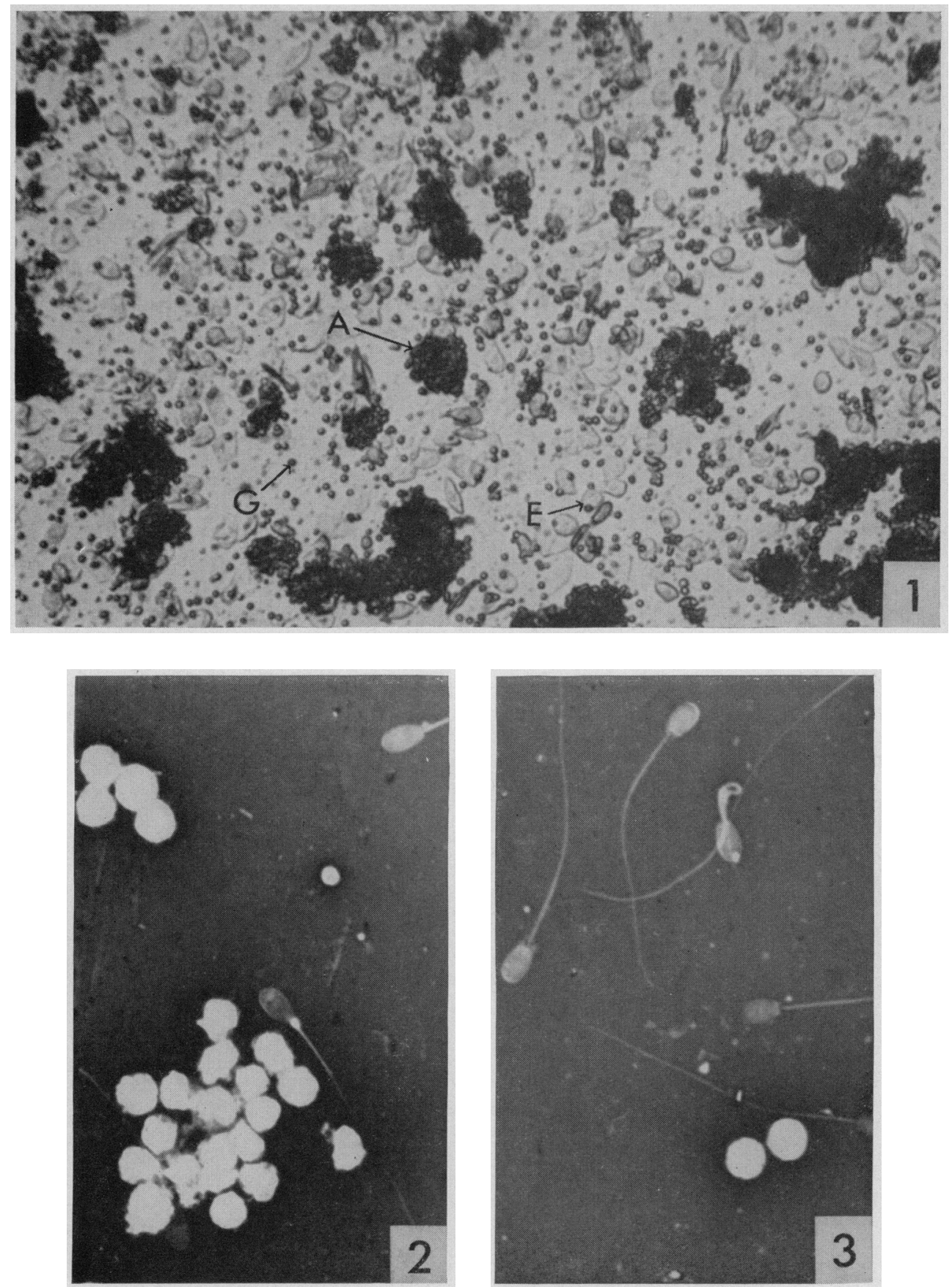

Fig. 1. Phase contrast photomicrograph illustrating 'globules' (C), aggregates of 'globule's' (A) and sloughed epithelial cells $(E)$ in the ejaculate of pubescent limbs. I12.

Fici. 2. Nigrosin-cosin-stained preparation showing large numbers of 'globules' at the time when spermateroa (with proximal droplets, first appeared in the cjaculate. \%667.

Fis. 3. Nigrosin cosin-staned preparation showing fewer 'globules' at the time when the number of spermatozoa increase's. I'he "globules" appear here to hatre a diameter about the same as the longer dianeter of the sperm head. 2667.

(Facing p. 482) 
Puberty in Suffolk and cross-bred rams

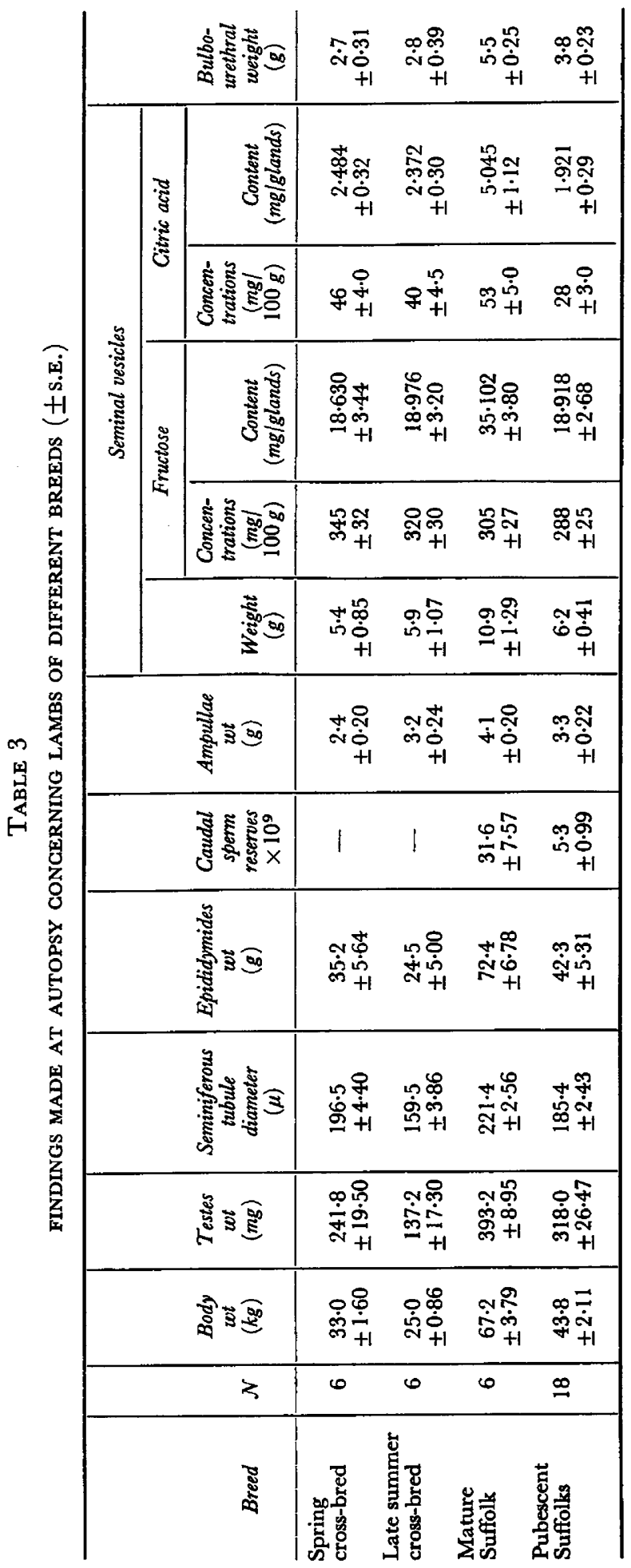


live weights, the weights of testes and accessory glands, the contents of fructose and citric acid in the seminal vesicles and extra gonadal sperm reserves. These

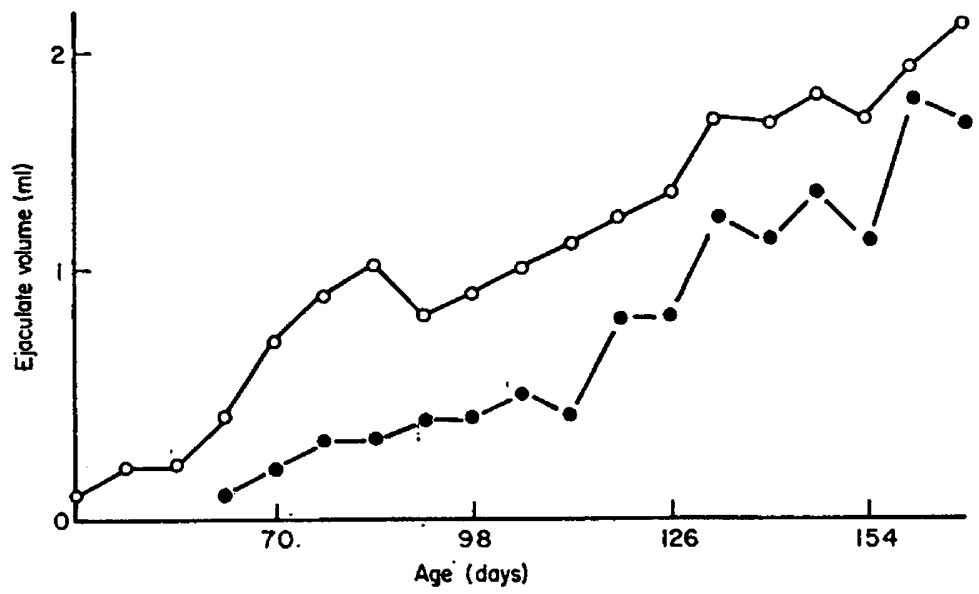

TEXT-FIG. 2. Mean ejaculate volume of six cross-bred lambs born in spring $(0)$ compared with the mean ejaculate volume of six lambs born in late summer (0).

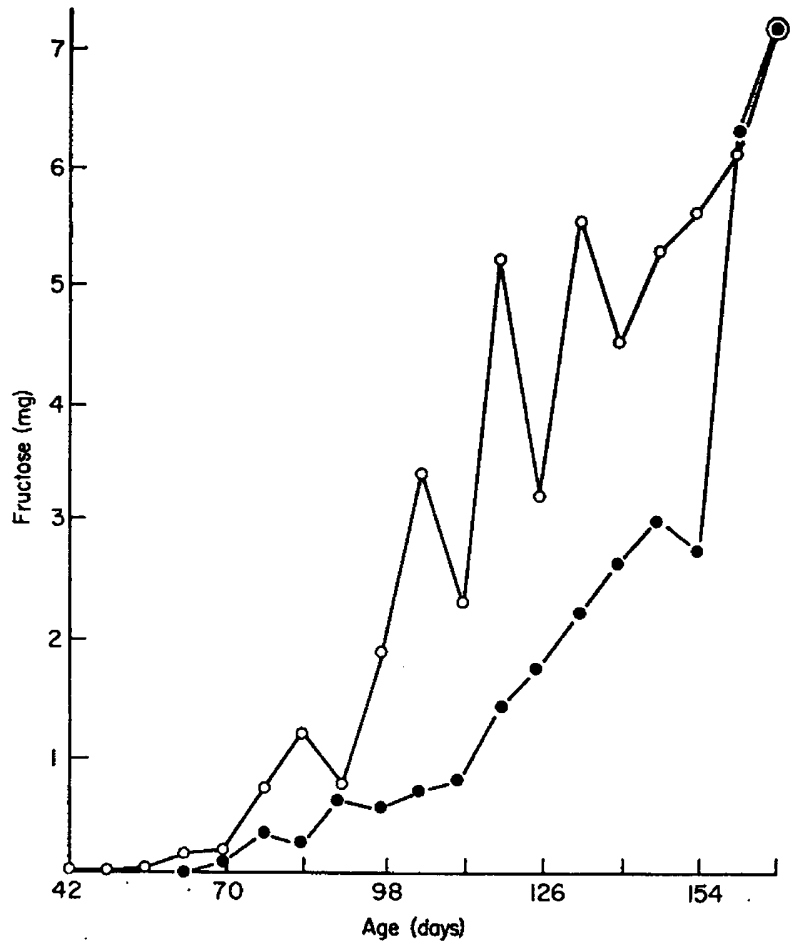

TeXT-Fig. 3. Mean total fructose content of the ejaculates from lambs born in spring (O) compared with the fructose content of those born in late summer $(\mathbf{\bullet})$

parameters are compared with those from mature Suffolks and it is apparent that, at 168 days of age, Suffolk lambs had attained $65 \%$ of mature live weight, $81 \%$ of testis weight and $64 \%$ of accessory gland weight. Sperm reserves in the 
cauda epididymidis were $17 \%$ of those in mature rams and $85 \%$ of the spermatozoa were motile.

The effect of season at which birth occurred, on the process of sexual development

Using the method of electro-ejaculation, it was possible to obtain ejaculates from spring lambs as early as 42 days of age. However, in lambs born later in the year, all attempts at collected ejaculates were unsuccessful until 63 days of age. In both groups of lambs, volume and fructose content increased steadily until 168 days of age. However, as can be seen from Text-figs. 2 and 3, the ejaculates of late summer lambs were smaller and contained less fructose until 154 days of age. But by 168 days of age in both groups of animals the values became similar. Spermatozoa appeared in the ejaculates of the spring lambs at 119 days and in the late summer lambs at 138 days. The time when spermatozoa first appeared in the ejaculate and the body weight attained by these animals at the same time are compared in Table 1. The live weights at autopsy, the weights of testes and accessory glands, and the contents of fructose and citric acid in the seminal vesicles are compared in Table 3. The spring lambs had a higher body weight, larger testes and a greater seminiferous tubule diameter than the late lambs. The epididymides of the spring lambs were heavier, probably as a result of containing many more spermatozoa, but the other accessory glands were lighter and the seminal vesicles contained less fructose and citric acid.

\section{DISCUSSION}

The lambs used in the present study were already displaying male behaviour by attempting to mount their companions at 28 days of age and they masturbated at 126 days of age. Libido therefore appears much earlier than spermatozoa. This has also been observed by other workers (Symington, 1961; Louw \& Joubert, 1964; Banks, 1964). In order to follow quantitatively the events of male pubescence in young rams, as reflected in the composition of semen, we decided to collect semen by electro-ejaculation. Although the artificial vagina gives more consistent results, Mattner \& Voglmayr (1962) found that electroejaculation is of equal value for studies relating to seminal fructose. Furthermore no training period is required when using electro-ejaculation and collections can begin before the adhesions between penis and prepuce have broken down under the influence of male hormone.

The time when it first becomes possible to collect a ram ejaculate coincides approximately with the time when androgens begin to be secreted in greater quantities by the lamb testis, and when the contents of fructose and citric acid rise steeply in the seminal vesicles (Skinner et al., 1968). The seminal ejaculates, however, displayed a much higher ratio of citric acid to fructose than the seminal vesicles as such $(10 \%$ reported by Skinner et al., 1968). In pubescent Suffolk lambs the seminal vesicles contain a small volume of secretion. In each of two 16 -week-old lambs, $0.2 \mathrm{ml}$ of vesicular secretion was collected from the gland and the levels of fructose and citric acid in the secretion compared with those in the vesicular tissue itself. The secretions contained 
$241 \mathrm{mg} / 100 \mathrm{ml}$ fructose and $110 \mathrm{mg} / 100 \mathrm{ml}$ citric acid, but the glandular tissue contained $250 \mathrm{mg} / 100 \mathrm{~g}$ and $35 \mathrm{mg} / 100 \mathrm{~g}$, respectively. Abdel-Raouf (1960) found a similar relationship in the pubescent calf. The ampullae, however, contain a higher percentage of citric acid. It is possible that the higher level of citric acid in the ejaculate is due either to a faster secretion rate of citric acid by the seminal vesicle, with less citric acid being retained within the gland itself, or to an additional contribution of citric acid by other accessory glands.

The time when 'globules' first appeared in ejaculates coincided approximately with the time when a lumen develops in the seminiferous tubules, that is 70 to 84 days (Skinner $e$ al., 1968). It is possible, therefore, that they emanate from the testis. However, at this stage of development the fructose and citric acid in the ejaculate also increased sharply and the 'globules' may have therefore been cleared from the ducts.

In the Suffolk rams, used in the present study, the penis had separated from the prepuce much earlier than in the other breeds studied, although liveweights were similar (Johnstone, 1948; Wiggens \& Terrill, 1953; Dun, 1955; Watson, Sapsford \& McCance, 1956; Belonje, 1965). This observation is in agreement with conclusions reached by the earlier investigators who stated that penis development proceeds more rapidly in heavier lambs and that it is dependent on general rate of growth. It is, however, possible that separation may have been advanced by the use of the electrical stimulation method which tends to induce protrusion of the penis and may thus have caused premature resolution of the adhesions.

It is apparent from the results given in Table 1 that spermatozoa appear in the ejaculates of the Suffolk ram at an earlier age than in all the other breeds so far studied, except the cross-bred lambs born in spring. These results are in accord with the histological findings reported by Skinner et al. (1968). The volume of the ejaculate when spermatozoa first appeared was greater than those recorded by Symington (1961) or Louw \& Joubert (1964). This difference may be due to differences in breed, environment or method of collection. The number of spermatozoa increased steadily from the time they first appeared. There was a concomitant increase in motility and a decrease in the numbers of abnormal spermatozoa (Table 2). Louw \& Joubert (1964) found a similar proportion of dead and abnormal spermatozoa when they first appeared, but 6 weeks afterwards only $6 \%$ of the spermatozoa from their rams were morphologically abnormal, compared with $9 \%$ primary abnormalities and $22 \%$ secondary abnormalities in the present study.

In mature Suffolks, sperm reserves in the cauda epididymidis are about $60 \%$ of total reserves in the epididymis (Dott \& Skinner, 1967) and observations in young rams are in agreement. On this basis, the total epididymal reserves in the present lambs would have been $8.8 \times 10^{9}$ which is greater than figures published for Merino rams of the same age (George \& Turnbull, 1966).

The reason for the low fructose levels in the ejaculates of lambs born late in the season may be related to the lower growth rate. Moule, Braden \& Mattner (1966) have found that fructose concentration in the ejaculate of the mature Merino is closely related to energy intake. The Suffolk spring lambs grew 
faster ( $200 \mathrm{~g} /$ day) than the late lambs ( $137 \mathrm{~g} /$ day) although both groups had a similar genetic background. This is in accordance with Hammond's (1932) finding that 'early' lambs grow faster than the 'late' ones, due in all probability to a seasonal difference in the level of nutrition. It would appear, therefore, that the 'late' lambs suffer primarily through reduced energy intake. On the other hand, the appearance of spermatozoa in the 'late' lambs was not markedly delayed. Thus it appears that the androgenic function of the testes is more markedly suppressed than spermatogenesis which agrees with results published on underfed calves (Davies, Mann \& Rowson, 1957; Mann \& Rowson, 1956, 1957). The levels of fructose and citric acid in ejaculates collected before autopsy, as well as in the seminal vesicles at autopsy, were higher in the late lambs. The early lambs were slaughtered in July and the late lambs at the beginning of December. British sheep breeds, including the Suffolk, are known to respond to shorter daylight length, showing greater sex drive (Chang, 1945; Cupps, McGowan, Rahlmann, Reddon \& Weir, 1960; Lees, 1965). Ortavant, Mauléon \& Thibault (1964) have published results showing a higher fructose concentration in the seminal vesicles of rams exposed to short daylight hours and Cupps et al. (1960) found fructose concentration in the ejaculate reached a maximum in Suffolks in October. It would appear, therefore, that the late lambs had an early nutritional handicap but they later enjoyed the advantage of shorter daylight hours just before slaughter.

In the past, two main definitions were used to describe the state of male puberty. While some authors, notably Asdell (1946), identify puberty with a fixed time related to the appearance of spermatozoa, others, including Marshall (1922) and, more recently, Donovan \& Werff ten Bosch (1965) prefer to view puberty as the stage in animal development when the endocrine function of the testes becomes clearly evident. The results of the present investigation favour the concept that the onset of male puberty coincides with the time when the testes become androgenically active, the accessory glands begin to secrete fructose and citric acid, and the animal assumes the characteristic male behaviour. Spermatozoa appear some time after the onset of male puberty.

\section{ACKNOWLEDGMENTS}

We would like to thank Dr H. M. Dott and Professor T. Mann for their interest in this work and for valuable advice. Mr J. Rowell calculated the correlation coefficients. One of us (J.D.S.) is indebted for a scholarship to British Petroleum (Southern Africa).

\section{REFERENCES}

Abdel-Raour, M. (1960) The postnatal development of the reproductive organs in bulls with special reference to puberty. Acta endocr., Copenh. Suppl. 49, 1.

Aspell, S. A. (1946) Patterns of mammalian reproduction, lst edn. Comstock, Ithaca, New York.

Banks, E. M. (1964) Some aspects of sexual behaviour in domestic sheep, Ovis aries. Behaviour, 23, 249.

Belonje, P. G. (1965) Observations on the postnatal development of the penis in Merino ram lambs and wethers: the possible relationship to the passage of urinary calculi. $\mathcal{H l} S$. Afr. vet. med. Ass. $36,381$.

Bцом, E. (1950) On the evaluation of bull semen with special reference to its employment for artificial insemination. A/S Carl Fr. Martenson, Copenhagen. 
Campbeli, R. C., Dotт, H. M. \& Glover, T. D. (1956) Nigrosin-eosin as a stain for differentiating live and dead spermatozoa. 7. agric. Sci., Camb. 48, 1.

Chang, M. C. (1945) The sperm production of adult rams in relation to frequency of semen collection. 7. agric. Sci., Camb. 35, 243.

Gupps, P. T., McGowan, B., Rahlmann, D. F., Reddon, A. R. \& Weir, W. C. (1960) Seasonal changes in the semen of rams. 7. Anim. Sci. 19, 208.

Davies, D. V., Mann, T. \& Rowson, L. E. A. (1957) Effect of nutrition on the onset of male sex hormone activity and sperm formation in monozygous bull-calves. Proc. $R$. Soc. B, 147, 332.

Donovan, B. T. \& WerfF ten Bosch, J. J. van DER (1965) Physiology of puberty. Edward Arnold, London.

Dotr, H. M. \& Skinner, J. D. (1967) A reassessment of extra gonadal sperm reserves in Suffolk rams. J. agric. Sci., Camb. 69, 293.

Dun, R. B. (1955) Puberty in Merino rams. Aust. vet. 7. 31, 104.

George, J. M. \& Turnbull, K. E. (1966) The effect of red clover pasture on the reproductive tract of ram lambs. Aust. 7. agric. Res. 17, 919.

Hammond, J. (1932) Growth and development of mutton qualities in the sheep. Oliver \& Boyd, Edinburgh.

Hay, Mary F., Lindner, H. R. \& ManN, T. (1961) Morphology of bull testes and seminal vesicles in relation to testicular androgens. Proc. $R$. Soc. B, 154, 433.

Johnstone, I. L. (1948) The growth and development of the penis in sheep: their possible relationship to posthitis. Aust. vet. F. 24, 86 .

LeEs, J. L. (1965) Seasonal variation in the breeding activity of rams. Nature, Lond. 207, 221.

LiNDNER, H. R. \& MANN, T. (1960) Relationship between the content of androgenic steroids in the testes and secretory activity of the seminal vesicles in the bull. F. Endocr. 21, 341 .

Louw, D. F. J. \& Jouber', D. M. (1964) Puberty in the male Dorper sheep and Boer goat. S. Afr. 7 . agric. Sci. 7, 509 .

Mann, T. (1946) Studies on the metabolism of semen. 3. Fructose as a normal constituent of seminal plasma. Site of formation and function of fructose in semen. Biochem. F. 40, 481.

MANn, T. (1964) Biochemistry of semen and of the male reproductive tract, 2nd edn. Methuen, London.

Mann, T., Davies, D. V. \& Humphrey, G. F. (1949) Fructose and citric acid assay in the secretions of the accessory glands of reproduction as indicator tests of male sex hormone activity. $\mathcal{J}$. Endocr. 6, 75.

Mans, T. \& Rowson, L. E. A. (1956) Effect of different planes of nutrition on the composition of bull semen. Proc. IIIrd int. Congr. Anim. Reprod. 1, 21.

ManN, T. \& Rowson, L. E. A. (1957) A study of the relationships between nutrition and reproduction in identical twin bulls. Proc. Nutr. Soc. 16, xviii.

Marshall, F. H. A. (1922) The physiology of reproduction, 2nd edn. Longmans Green, London.

Mattner, P. E. \& Voglmayr, J. K. (1962) A comparison of ram semen collected by the artificial vagina and by electro-ejaculation. Aust. 7. exp. Agric. Anim. Husb. 2, 78.

Moule, G. R., Braden, A. W. H. \& Mattner, P. E. (1966) Effects of season, nutrition and hormone treatment on the fructose content of ram semen. Aust. 7. agric. Res. 17, 923.

Ortavant, R., Mauléon, P. \& Thibault, C. (1964) Photoperiodic control of gonadal and hypophysial activity in domestic animals. Ann. N.Y. Acad. Sci. 117, 157.

RoE, J. H. (1934) A colorimetric method for the determination of fructose in the blood and urine. J. biol. Chem. 107, 15.

Rowson, L. E. A. \& Murdoch, M. I. (1954) Electrical ejaculation in the bull. Vet. Rec. 66, 326.

Skinner, J. D., Booth, W. D., Rowson, L. E. A. \& KARG, H. (1968) The post-natal development of the reproductive tract of the Suffolk ram, and changes in the gonadotrophin content of the pituitary. 7. Reprod. Fert. 16, 463.

Speck, J. F., Moulder, J. W. \& Evans, E. A., JR. (1946) The biochemistry of the malaria parasite. J. biol. Chem. 164, 119.

Symington, R. B. (1961) Studies on the adaptability of three breeds of sheep to a tropical environment modified by altitude. VII. Sexual activity in relation to age of ram. 7. agric. Sci., Camb. 56, 179.

Watson, R. H., SAPsforb, C. S. \& MCGance, I. (1956) The development of the testis, epididymis and penis in the young Merino ram. Aust. 7 . agric. Res. $7,574$.

Wiggins, E. L. \& Terrill, C. E. (1953) Variation in penis development in ram lambs. 7 . Anim. Sci. 12,524 . 